\title{
MDR BACTERIAL INFECTIONS IN CRITICALLY ILL COVID-19 PATIENTS IN A TERTIARY CARE HOSPITAL (OF PAKISTAN)
}

\author{
Nadia Tayyab, Warda Furqan, Amnah Nasrullah, Javaid Usman*, Sakhawat Ali, Asad Zaman Khan \\ Pak Emirates Military Hospital/National University of Medical Sciences (NUMS) Rawalpindi Pakistan, *Army Medical College/National University of Medical \\ Sciences (NUMS) Rawalpindi Pakistan
}

\begin{abstract}
Objective: To identify antimicrobial susceptibility pattern of multidrug resistant bacteria causing secondary infections in COVID-19 patients in ICU' sofa tertiary care hospital.

Study Design: Cross-sectional study.

Place and Duration of Study: Department of Microbiology, Pak Emirates Military Hospital, Rawalpindi, from Apr to Jul 2020. Methodology: This study included blood samples and endotracheal aspirates from 114 critically ill COVID-19 patients. Peripheral blood specimens were collected fromthe patients with secondary bacterial blood stream infections and endotracheal aspirates were collected from patients with ventilator associated pneumonia for culture and sensitivity. The results were interpreted according to Clinical \& Laboratory Standard Institute (CLSI) 2020.

Results: A total of 114 COVID-19 patients were admitted in ICU during that time period. Fourteen (12.28\%) were female and $100(87.71 \%)$ were male, age distribution was between $36-82$ years. Sixty six paired blood samples were sent to the microbiology lab out of which 51 (77.2\%) showed bacterial growth while $15(22.7 \%)$ samples were negative. Out of 50 endotracheal aspirates, 42 showed bacterial growth $(84 \%)$ and 8 samples did not show any significant bacterial growth (16\%). Most of the endotracheal aspirates showed growth of $>1$ bacterial isolates. The most common gram-negative organisms were Acinetobacter baumannii $(\mathrm{n}=54)$ and Klebsiella pneumonia $(\mathrm{n}=26)$ and most common gram-positive organism isolated was Enterococcus faecium $(\mathrm{n}=9)$. All isolated organisms were multidrug resistant.

Conclusion: Poor antimicrobial stewardship particularly in critical care units resulted in secondary bacterial infections in COVID-19 patients. The pathogens isolated were multidrug resistant including Acinetobacter baumannii, Klebsiella pneumonia and Enterococcus faecium.
\end{abstract}

Keywords: Blood cultures, COVID-19, Endotracheal aspirates, Multidrug resistant isolates, Secondary bacterial infections.

This is an Open Access article distributed under the terms of the Creative Commons Attribution License (https://creativecommons.org/licenses/by-nc/4.0/), which permits unrestricted use, distribution, and reproduction in any medium, provided the original work is properly cited.

\section{INTRODUCTION}

COVID-19 pandemic has become the biggest challenge for the healthcare system and economies of developing as well as developed countries. Up till $1^{\text {st }}$ August 2020, globally 17,396,943 COVID confirmed cases have been reported and 675,060 deaths have been registered ${ }^{1}$. According to ministry of national health services, regulations and coordination Pakistan, there are 279,699 lab confirmed COVID-19 cases with total of 5,976 deaths $^{2}$.

Viral pneumonia can be complicated by bacterial and fungal infections. Bacterial coinfections have been reported in patients of influenza in $0.5 \%$ of young healthy patients and $2.5 \%$ of older age groups ${ }^{3}$. Secondary bacterial infections have also resulted in fatal outcome during H1N1 pandemic 20094. As many patients with severe disease require ICU admissions and mechanical ventilation, the risk of hospital-acquired infections with multidrug resistant organisms (MDROs) and fungal isolates has further added burden on health care

Correspondence: Dr Nadia Tayyab, Consultant Microbiologist, Pak Emirates Military Hospital, Rawalpindi Pakistan

Received: 13 Oct 2020; revised received: 14 Dec 2020; accepted: 16 Dec 2020 system. Intensive care units (ICUs) must be prepared for challenges associated with this pandemic ${ }^{5}$. There have been reports of rise in nosocomial bacterial co infections in COVID-19 patients 6 . There is also high risk of acquiring fungal infections like invasive Aspergillosis, in patients who develop acute respiratory distress syndrome (ARDS) following viral infections ${ }^{7}$. These infections cannot only result in increased mortality but can lead to prolonged hospital stay with exhaustion of medical services and resources.

Most of the studies conducted during this pandemic have focused on SARS-CoV-2 transmission and its prevention, cytokine release syndrome (CRS) and trials for effective and safe treatment options ${ }^{8}$. Up till now, only limited number of studies have been published regarding secondary bacterial infections in these patients. One of the study conducted in China showed that during COVID-19 pandemic $50 \%$ of patients with COVID had died due to secondary bacterial infections ${ }^{9}$.

In this study, blood culture specimens from septicemic patients as well as endotracheal aspirates from patients withventilator associated pneumonia (VAP) 
were processedfor culture and sensitivity so that timely and targeted antimicrobial therapy could be initiated and local (epidemiological) antimicrobial data generated for empirical use. Moreover, these hospitals acquired infections can be prevented byincreasing awareness and strict implementation of infection control practices.

\section{METHODOLOGY}

This cross-sectional study was conducted at the Pak Emirates Military Hospital (PEMH) Rawalpindi. It is 1100 bedded hospital which was dedicated exclusively for patients of COVID-19 during that time period. In this study samples were collected, from April to July 2020 from ICU patients only. Non probability consecutive sampling technique was used. Permission was obtained from the ethics review committee and Institutional Review Board. Informed consent was not required from all the patients for the study. Data and patient identification (ID) included in this study remains confidential.

Endotracheal aspirates were collected fromonly those patients who had remained on invasive ventilation forat least a minimum period of three daysand fulfilled clinical definition of VAP as per Up-to-date guidelines ${ }^{10}$. Paired peripheral blood cultures were taken from the patients with clinical suspicion of blood stream infections and raised inflammatory markers including procalcitonin.

Culture specimens received in Microbiology Lab PEMH were processed according to standard microbiological guidelines. Blood culture bottles were incubated in automated BacT/ALERT BD Biomerieux microbial identification system (USA). Specimens from signal positive blood culture bottles were sub cultured on 5\% sheep blood agar and MacConkey agar plates irrespective of gram stain findings. These agar plates were then incubated at $35^{\circ} \mathrm{C}$ in ambient atmospheric conditions for 24 hours to see for any visible bacterial growth. Based on gram stain results, catalase and coagulase tests were done on gram-positive cocciwhich were further identified by biochemical reactions on analytical profile index (API) for Staphylococci and Streptococci (Biomerieux, France). For Gram-negative rods, oxidase test was done and exact identification was done by API20E (Biomerieux, France). For Entero-bacterales and API20NE for non Enterobacterales (Biomerieux, France).

Endotracheal aspirates were inoculated manually according to standard microbiological guide lines on $5 \%$ sheep blood agar, MacConkey agar, Chocolate agar and Sabouraud's agar. These agar plates were then incubated and bacterial growth obtainedidentified as per blood culture isolates.

Modified Kirby Bauer disc diffusion method on Muller Hinton agar (Oxoid, UK) was used to report antimicrobial susceptibility testing. Recommended anti microbial discs of different concentrations for respective isolates were applied as per CLSI guidelines 2020. For Polymyxin E/Colistin, susceptibilityin Enterobacterales, Colistin agar dilution method atcolistin concentrations of $2 \mathrm{ug} / \mathrm{ml}$ and $4 \mathrm{ug} / \mathrm{mlwas}$ used. For Acinetobacter baumannii. Broth micro dilution was done. Results were interpreted according to Clinical \& Laboratory Standards Institute (CLSI) guidelines 202011.

Escherichia coli (E.coli) ATCC 25922, Pseudomonas aeruginosa (P. aeruginosa) ATCC 27853 and Staphylococcus aureus (S. aureus) ATCC 25923 were used as control strains. Screening of Methicillin Resistant Staphylococcus aureus (MRSA), mec A mediated oxacillin resistance was detected by using cefoxitin (30ug) disc. Resistance to ceftazidime (30ug) disc was used as a screening method for detection of extended spectrum beta lactamase (ESBL), confirmed by ESBL test as recommended by CLSI guidelines 2020.

SPSS-22 was used for statistical analysis of data. Demographic data was assessed using descriptive statistics. Mean and standard deviation were collected for numerical variables like age. Categorical variables were expressed using frequency and percentages. The $p$-value $\leq 0.05$ were considered statistically significant.

\section{RESULTS}

We analyzed data of culture specimens collected from COVID-19 patients admitted in ICUs. Specimens were collected from two different patient populations, patients who developed secondary bacterial blood stream infections and patients who developed VAP during the period starting on April 2020 and ending on July 2020. During this time 114 patients were admitted in ICU. Few patients were directly admitted to this unit due to need for invasive as well as non-invasive ventilation depending on increased respiratory rate, falling oxygen saturation and increased oxygen requirement, while most of the patients were shifted from step down wards/general wards due toworsening of symptoms. Out of these 114 patients, 14 (12.28\%) females and $100(87.71 \%)$ were males, average age was 58 yrs. Average age distribution was between $36-82$ yrs.

Twenty (17.5\%) patients with secondary bacterial infections had both diabetes and hypertension. 
Paired blood cultures from 66 patients with suspected blood stream infections were sent to microbiology lab for bacterial isolation and antimicrobial susceptibility testing. Blood cultures of remaining 48 patients were not received as few patients expired within 24 hours after being admitted to ICU and some patients were shifted back to stable wards due to improvement in symptoms within three days of ICU stay. Out of 66 blood culture specimens, 51 (77.2\%) showed bacterial growth while $15(22.7 \%)$ samples were negative after 5 days of incubation at $37^{\circ} \mathrm{C}$ by automated blood culture system.

Out of 51 positive blood culture specimens. Forty three showed growth of same isolate in both specimens of paired samples whereas 8 showed growth of isolate only in single specimenout of paired sample. Bacteria isolated from paired blood culture specimens in decreasing order of frequency were Acinetobacter $b a-$ umannii 22 (51.16\%), Klebsiella pneumoniae 10 (23.25\%), Enterococcus faecium 6 (13.9\%), E.coli 2 (4.65\%), Citrobacter freundii 1 (2.32\%), MRSA 1 (2.32\%) and Stenotrophomonas maltophilia 1 (2.32\%) (fig-1).

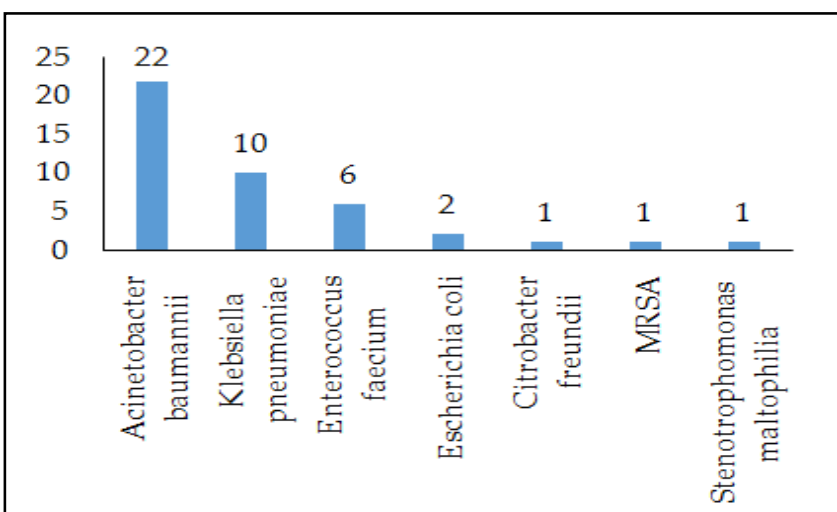

Figure-1: Frequency of organisms isolated from blood cultures.

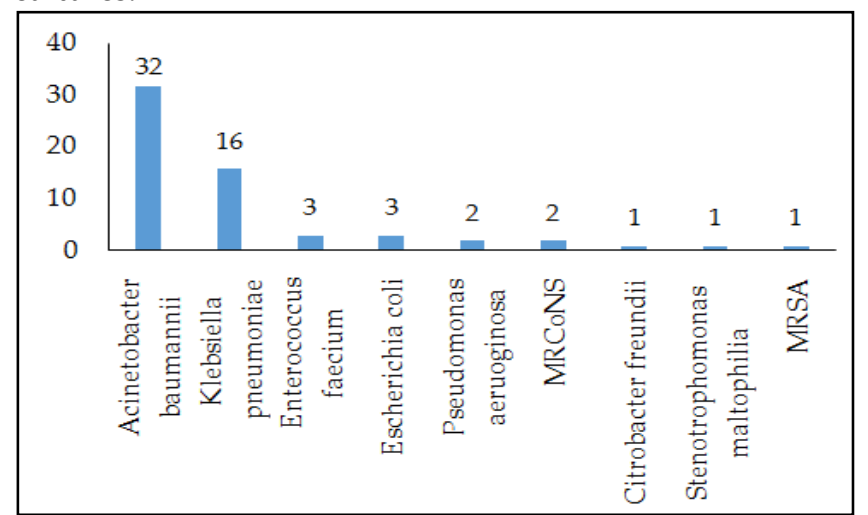

Figure-2: Frequency of bacterial isolates from endotracheal aspirates.
Total 50 endotracheal aspirates fulfilling acceptance criteria were processed at microbiology lab for culture and sensitivity. Out of which, 42 showed bacterial growth (84\%) and 8 samples did not show any significant bacterial growth (16\%). Most of the endotracheal aspirate showed growth of $>1$ bacterial isolates (fig-2).

Organisms isolated in 42 samples were Acinetobacter baumannii 32 (76.1\%), Klebsiella pneumoniae 16 (38.0\%), Escherichia coli 3 (7.14\%), Enterococcus faecium $3(7.14 \%)$, Pseudomonas aeruginosa 2 (4.76\%), MRCoNS $2(4.76 \%), M R S A 1(2.38 \%)$ and Citrobacter freundii 1 $(2.38 \%)$.

Table-I shows that most frequently isolated Gram positive organism in blood and endotracheal aspirates was Enterococcus faecium. Enterococcus faecium was uniformly susceptible to linezolid, whereas two isolates were resistant to vancomycin.

Table-I: Comorbidities in critically ill COVID-19 patients.

\begin{tabular}{l|c|c} 
& Frequency & Percentage \\
\hline No comorbidities & 39 & 34.21 \\
\hline Hypertension & 14 & 12.28 \\
\hline Diabetes & 10 & 8.77 \\
\hline Pneumonia & 9 & 7.89 \\
\hline DM, HTN, Pneumonia & 6 & 5.26 \\
\hline DM, HTN & 20 & 17.54 \\
\hline DM, HTN, OBESITY & 4 & 3.54 \\
\hline DM, IHD, HTN & 3 & 2.63 \\
\hline DM,Pneumonia & 3 & 2.63 \\
\hline IHD, Pneumonia & 2 & 1.75 \\
\hline Pneumonia, Down & 1 & 0.87 \\
Syndrome & 1 & 0.87 \\
\hline Pulmonary TB & 1 & 0.87 \\
\hline Myasthenia Gravis & 1 & 0.87 \\
\hline DM, DVT & 114 & 100 \\
\hline Total & &
\end{tabular}

Table-II shows that among blood and endotracheal cultures, the most common bacterial isolate was Acinetobacter baumannii. Most of the isolates were highly drug resistant, sensitive only to minocycline, tigecycline and colistin. All isolates of Acinetobacter baumannii and Klebsiella pneumoniae showed resistance to the carbapenems. It has been observed that patients whose specimens showed growth of these resistant bugs had prolong hospital stayranging from 3-22 days with most of the cases had fatal outcome. 
Antimicrobial therapy was tailored according to culture and sensitivity reports as most of the patients were already on broad spectrum anti-microbials due to high grade fever, new pneumonic patch on chest $\mathrm{x}$-ray and rising trends in inflammatory markers. responded to antimicrobial therapy and were recovered but 32 patients did not survive. Our results were more worrisome as compared to a study conducted in China during same pandemic in which there were 15\% hospital acquired secondary infections which caused

Table-II: Antimicrobial resistance pattern for enterococcus faeciumin blood and endotracheal aspirates.

\begin{tabular}{c|c|c|c|c|c|c|c}
\hline $\mathbf{N}$ & PEN & AMP & AMC & ERY & LZD & VAN & CAP \\
\hline 9 & 9 & 9 & 9 & 9 & 0 & 2 & 4 \\
\hline Resistance percentage & $100 \%$ & $100 \%$ & $100 \%$ & $100 \%$ & 0 & $22.2 \%$ & $44.4 \%$ \\
\hline
\end{tabular}

PEN=Penicillin, AMP=Ampicillin, ERY=Erythromycin, LZD=Linezolid, VAN=vancomycin, $C A P=$ Chloramphenicol.

Table-III: Antimicrobial resistance pattern for most commonly isolated gram negative organisms.

\begin{tabular}{|c|c|c|c|c|c|c|c|c|c|c|c|c|c|c|c|c|}
\hline $\begin{array}{c}\text { Gram } \\
\text { negative } \\
\text { organisms }\end{array}$ & $\approx$ & $\sum_{k}^{k}$ & 光 & 㒻 & $\sum_{4}^{u}$ & $\begin{array}{l}0 \\
\approx\end{array}$ & $\sum_{\substack{\mid=1 \\
\sum}}$ & 它 & w & ¿ & Z & 氙峾 & $\stackrel{\hat{N}}{F}$ & $\sum_{u}^{N}$ & $\sum_{\substack{U \\
U}}$ & U \\
\hline $\begin{array}{c}\text { Acinetobacter } \\
\text { baumannii }\end{array}$ & 苛 & $\cong$ & $\ddot{n}$ & में & $\cong$ & $\mathbb{H}$ & हn & Lt & Ln & $\cong$ & in & $\stackrel{\infty}{\sim}$ & Hn & 苛 & Hै & లి \\
\hline $\begin{array}{l}\text { Resistance } \\
\text { percentage }\end{array}$ & & 当 & $\stackrel{\circ}{8}$ & $\stackrel{\circ}{\circ}$ & $\because$ & ஓ̊ & $\stackrel{\circ}{8}$ & $\stackrel{\circ}{8}$ & $\stackrel{\circ}{8}$ & $\cong$ & ڤे & $\begin{array}{l}\stackrel{0}{m} \\
\ddot{m} \\
\ddot{n}\end{array}$ & $\stackrel{\circ}{8}$ & $\stackrel{\circ}{8}$ & $\stackrel{\circ}{\circ}$ & 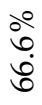 \\
\hline $\begin{array}{c}\text { Klebsiella } \\
\text { pneumoniae }\end{array}$ & $\stackrel{\sim}{\sim}$ & $\cong$ & $\stackrel{\infty}{\sim}$ & సి & $\stackrel{\sim}{N}$ & సి & $\stackrel{\stackrel{\llcorner}{N}}{ }$ & $\stackrel{\sim}{\sim}$ & ㄹ & $\cong$ & $\approx$ & I & $\stackrel{\sim}{N}$ & $\stackrel{\sim}{N}$ & ֻ & + \\
\hline $\begin{array}{l}\text { Resistance } \\
\text { percentage }\end{array}$ & & $\underline{v}$ & ڤें & $\stackrel{\circ}{8}$ & $\stackrel{\circ}{\circ}$ & $\stackrel{\circ}{8}$ & ஓ̊ & $\stackrel{\circ}{\circ}$ & $\stackrel{\circ}{\circ}$ & $\cong$ & $\begin{array}{l}\text { ले } \\
\text { மூं }\end{array}$ & ' & $\stackrel{\circ}{8}$ & $\stackrel{\circ}{8}$ & 。̊ & $\begin{array}{l}0_{0}^{\circ} \\
\stackrel{m}{10}\end{array}$ \\
\hline
\end{tabular}

$A K=$ Amikacin, GEN=Getamicin, AMC=CoAmoxiclav, $C R O=$ Ceftriaxone, $M E M=$ Meropenem, $S X T=$ Cotrimoxazole,

MIN=Minocycline, $C T / P E=$ colistin/polymyxinE, TZP=piperacillin-tazobactum, CAZ=ceftazidime, $C F M=$ cefepime, TGC=Tigecycline.

\section{DISCUSSION}

Secondary bacterial infections in critical care setting sare not a new dilemma. For past many years it has not only resulted in high mortality 12 but also put a huge burden on hospital resources as well as selection of highly drug resistant strains. Also in patients of COVID-19 in ICUs secondary bacterial infections can further worsen the prognosis ${ }^{13}$. In our study, majority of patients admitted in ICU and placed on invasive ventilations had superadded bacterial infections. Many of these patients developed high grade fever, thick respiratory secretions along with raised inflammatory markers including CRP, Ferritin and LDH. Due to clinical suspicion of septicemia and VAP multiple paired blood cultures and endotracheal aspirates were collected and sent to microbiology lab for culture and sensitivity.

Patients in our studywho developed VAP remained on ventilators for $>72$ hours with range lying between 3-22 days (average 9 days). Out of positive tracheal aspirates from 42 patients, only 10 patients mortality of $30 \%$ patients ${ }^{14}$. Most of our ICU patients were on azithromycin along with meropenem or ceftriaxone. Other studies also showed that patients with viral infections involving lower respiratory tract, including COVID-19, were often administered prophylactic antibiotics, including azithromycin, moxifloxacin, ceftriaxone, vancomycin, or cefepime, to reduce the risk of secondary infections; often in addition to another antibiotic that is initiated once the isolate is identified ${ }^{15,16}$. As the numbers of antibiotic-resistant bacterial strains continue to grow, there is increased risk of bacterial and fungal superinfections especially in intensive care units (ICUs).

In our study many patients with bacterial coinfections have co-morbidities such as diabetes mellitus, hypertension, ischemic heart disease and obesity. Old age was also associated with slow recovery and delayed response to therapeutic measures. Age of most of the patients was between 56-58 years. We observed that patient with secondary bacterial infections had prolonged hospital stay and increased mortality as these findings are in accordance with the previous 
studies conducted on coinfections in pandemic due to respiratory viruses ${ }^{17,18}$.

MDROs isolated alone from endotracheal aspirates may indicate VAP but differentiation of actual pathogens causing VAP from colonizers of endotracheal tubes is difficult in the absence of other clinical findings. In our study all positive tracheal aspirates were from those patients who clinically had deterioration of respiratory symptoms with thick tracheal secretions along with rising trend in inflammatory markers and progressing opacities on $\mathrm{x}$-ray chest.

Bacteria isolated from positive blood cultures as well as endotracheal aspirates were mainly gramnegative rods (GNRs). Our results are comparable to a cohort study conducted in Spain in which GNRs played a vital role in ICU acquired secondary infections ${ }^{19}$. Among gram-negative bacteria, most commonly isolated bacterium was Acinetobacter baumannii which was XDR isolate. According to a study conducted in China, highly drug resistant Acinetobacter baumannii was isolated among 99 critically ill patients with secondary bacterial infections which is similar to our study ${ }^{20}$. Other GNRs include Klebsiella pneumonia, E.coli, Citrobacter freundii. As per CLSI there are no established breakpoints for tigecycline among gram negative rods isolated from blood but we tested this drug following EUCAST guidelines zones for Enterobacterales 21 as we had left with very less antimicrobial options. Among gram positive isolates, all were gram positive cocci (GPC). Enterococcus faecium was most frequently isolated followed by MRCoNS and MRSA.

Our study also showed that although severe COVID-19 pneumonia and subsequent CRS is associated with highmorbidity and mortality but those patients who developed hospital acquired infections had rapid deterioration of symptoms and poorclinical outcome. Empirical broad spectrum intravenous antimicrobial therapy was started after collecting culture specimens in many of the patients who were shifted to ICU from other wards due to deterioration of symptoms. Later on antimicrobial therapy was tailored according to susceptibility results. Response to antimicrobials was poor as most of these bacterial isolates were highly drug resistant with very limited treatment options. Nosocomial infections are becoming more common due to the rise of resistant bacterial pathogens. Alternative antibacterial therapeutic strategies are needed; such as phage therapy or phage-derived therapeutic proteins for better clinical outcome ${ }^{22}$.
Further multicenter studiesare required to collect sufficient and reliable data regarding secondary bacterial infections in these patients so that effective and timely management can reduce morbidity and mortality due to these super added bacterial infections.

\section{CONCLUSION}

Due to SARS-CoV-2 pandemicthere is already a huge burden on health care management system all over the world regarding its containment, prevention and management. As all resources including man power, infrastructure and economy are being utilized to their maximum extent to overcome this disease, there is a need to control these hospitals acquired infections. Moreover, in developing countries with resource constraints including Pakistan, these hospitals acquired highly resistant secondary bacterial infections have further added burden onour health care system. Antimicrobial stewardship and strict infection control practices have a pivotal role in curtailing these resistant infections for better clinical outcome.

Co-infection is possible among COVID-19 patients. Clinicians cannot rule out co-infection with other respiratory pathogens when diagnosing SARS-CoV-2 infection nor rule out COVID-19 by detecting nonSARS-CoV-2 respiratory pathogens. However, our findings were based on a limited number of patients in ICU of one hospital. Further large-sample, well-designed studies are warranted to have reliable data regarding prevalence of COVID-19 secondary bacterial infections, microbiological distribution, and impact of these infectionson the clinical outcome of the patients. After obtaining more data regarding secondary bacterial infections or bacterial co-infections with SARSCoV-2, we can reach a consensus regarding initiation of appropriate empirical antimicrobial therapyin critically ill COVID-19 cases.

\section{CONFLICT OF INTEREST}

This study has no conflict of interest to be declared by any author.

\section{REFERENCES}

1. World Health Organization. Coronavirus disease 2019 (COVID19): situation report, 1942020 [Internet] Available at: https:// www.who.int/docs/default-source/coronaviruse/situationreports $/ 20200801$-covid-19-sitrep-194.pdf?sfvrsn $=401287 f 3 \_2$.

2. Government of Pakistan. Coronavirus in Pakistan Confirmed Cases 2020 [Internet] Available at: http://covid.gov.pk/. [Accessed on: Aug 1, 2020]

3. Ramírez-Palacios LR, Reséndez-Pérez D, Rodríguez-Padilla MC, Saavedra-Alonso S, Real-Najarro O, Fernández-Santos NA, et al. Molecular diagnosis of microbial copathogens with influenza A (H1N1) pdm09 in Oaxaca, Mexico 2018; 9(1): 49-62. 
4. Rice TW, Rubinson L, Uyeki TM, Vaughn FL, John BB, Miller III RR, et al. Critical illness from 2009 pandemic influenza A (H1N1) virus and bacterial co-infection in the United States. Crit Care Med 2012; 40(5): 1487-98.

5. Phua J, Weng L, Ling L, Egi M, Lim C-M, Divatia JV, et al. Intensive care management of coronavirus disease 2019 (COVID-19): challenges and recommendations2020 [Internet]. Available from: https:// pubmed.ncbi.nlm.nih.gov/32272080/. [Accessed on Aug $1,2020]$.

6. Rawson TM, Moore LS, Zhu N, Ranganathan N, Skolimowska K, Gilchrist $\mathrm{M}$, et al. Bacterial and fungal co-infection in individuals with coronavirus: A rapid review to support COVID-19 antimicrobial prescribing 2020 [Internet]. Available from: https:// pubmed.ncbi. nlm.nih.gov/32358954/.

7. Lai CC, Wang CY, Hsueh P-R. Co-infections among patients with COVID-19: The need for combination therapy with non-antiSARS-CoV-2 agents. J Microbiol Immunol Infect 2020; 53(4): 50512.

8. Adhikari SP, Meng S, Wu Y-J, Mao Y-P, Ye R-X, Wang Q-Z, et al. Epidemiology, causes, clinical manifestation and diagnosis, prevention and control of coronavirus disease (COVID-19) during the early outbreak period: a scoping review. Infect Dises Poverty 2020; 9(1): 1-12.

9. Cox MJ, Loman N, Bogaert D, O'grady J. Co-infections: potentially lethal and unexplored in COVID-19. Lancet Microbe 2020; 1(1): e11-15.

10. Kollef M, Bartlett JG. Clinical presentation and diagnostic evaluation of ventilator-associated pneumonia 2017 [Internet]. Available from: https://www.uptodate.com/contents/clinicalpresentation-and-diagnostic-evaluation-of-ventilator-associatedpneumonia. [Accessed on Aug. 01, 2020].

11. CLSI. Performance Standards for Antimicrobial Susceptibility Testing. 2020; 30th ed, Available at [Internet]. https://www.nih. org.pk/wp-content/uploads/2021/02/CLSI-2020.pdf

12. Hong KH, Choi JP, Hong SH, Lee J, Kwon JS, Kim SM, et al.
Predictors of mortality in middle east respiratory syndrome (MERS) 2018; 73(3): 286-89.

13. Zhu X, Ge Y, Wu T, Zhao K, Chen $Y, W u$ B, et al. Co-infection with respiratory pathogens among COVID-2019 Cases. Virus Res 2020: 285(1); 198005-12.

14. Zhou F, Yu T, Du R, Fan G, Liu Y, Liu Z, et al. Clinical course and risk factors for mortality of adult inpatients with COVID-19 in Wuhan, China: a retrospective cohort study 2020 Lancet 2020; 395(10229): 1054-62.

15. Holshue ML, DeBolt C, Lindquist S, Lofy KH, Wiesman J, Bruce $\mathrm{H}$, et al. First case of 2019 novel coronavirus in the United States 2020; N Engl J Med 2020; 382(10): 929-36.

16. Wang D, Hu B, Hu C, Zhu F, Liu X, Zhang J, et al. Clinical characteristics of 138 hospitalized patients with 2019 novel coronavirus-infected pneumonia in Wuhan, China. J Am Med Assoc 2020; 323(11): 1061-69.

17. Burrell A, Huckson S, Pilcher DV. ICU admissions for Sepsis or pneumonia in Australia and New Zealand in 2017. N Engl J Med 2018; 378(22): 2138-39.

18. Martin-Loeches I, Schultz MJ, Vincent JL, Alvarez-Lerma F, Bos LD, Solé-Violán J, et al. Increased incidence of co-infection in critically ill patients with influenza. Intensive Care Med 2017; 43(1): 48-58.

19. Garcia-Vidal C, Sanjuan G, Moreno-García E, Puerta-Alcalde P, Garcia-Pouton N, Chumbita M. Incidence of co-infections and superinfections in hospitalised patients with COVID-19: a retrospective cohort study. Clin Microbiol Infect 2021; 27(1): 83-88.

20. Chen N, Zhou M, Dong X, Qu J, Gong F, Han Y, et al. Epidemiological and clinical characteristics of 99 cases of 2019 novel coronavirus pneumonia in Wuhan, China: a descriptive study. Lancet 2020; 395(10223): 507-13.

21. Manohar P, Loh B, Athira S, Nachimuthu R, Hua X, Welburn SC, et al. Secondary bacterial infections during pulmonary viral disease: phage therapeutics as alternatives to antibiotics? 2020(11): 1434-38. 